\title{
Resistance to PPE Using by Gas Station Attendants
}

\author{
Ananda Vieira de Lima Almeida ${ }^{1 *}$, Vitor Erick Cardoso Freitas ${ }^{1}$ \\ ${ }^{1}$ Senai Cimatec University Center; Salvador,Bahia, Brazil
}

\begin{abstract}
The discussion about the use, or not, of Personal Protective Equipment (PPE) by gas station attendants has been growing, in the contemporary context, due to the expansive increase in the consequences generated by the absence of this essential equipment at gas stations. The present study highlighted the importance of raising awareness among the attendants regarding their working conditions, mainly due to the high exposure to toxic compounds. At this core, resistance to use PPE by these workers comesfrom sociocultural issues that notoriously influence the conditionsimposed by this service. In this logic, the case study, determined by the book of Research Methodology by Marconi and Lakatos (2003), thistheme is based on data collection at gasstationsin the city of Salvador- BA, in 2021, to highlight the situations faced by these professionals and, consequently, the impacts on their quality of life and health. The resistance to the use of this equipment harms the present and future wellbeing of the attendants. Keywords: Gas Station Attendants. PPEs. Risks.
\end{abstract}

\section{Introduction}

The growing demand for fuel in Brazil boosted the discussions about the attendants. The exposure suffered by these workers when performing their function leads the present study to highlight the resistance of using PPE by the attendants. In this context, it is worth noting that gasoline contamination - the principal fuel at stations emphasizes an unhealthy work environment, according to article 189 of the Consolidation of Labor Laws (CLT), which drives serious problems related to worker health and, consequently, the maximization of questions about the role of PPE as a prophylactic measure [1].

Therefore, the resistance of gas station attendants regarding PPE comes from the lack of knowledge about the consequences of exposure to gasoline since toxicity is the main factor to be considered [2].

In this scenario, the Ministry of Labor, through Regulatory Standard 9 and 12 (NR-9 and NR-12)

Received on 12 August 2021; revised 28 November 2021. Address for correspondence: Ananda Vieira de Lima Almeida. Av. Orlando Gomes, 1845 - Piatã, Salvador - BA- Brazil. Zipcode: 41650-010. Phone: (71) 3462-8449. E-mail: anandavlalmeida@hotmail.com.

J Bioeng. Tech. Appl. Health 2021;4(4):117-127.

C 2021 by SENAI CIMATEC. All rights reserved. and Ordinance No. 25/1994, classifies occupational risks into five types: physical, chemical, biological, ergonomic, and accidental, which are essential to assimilate the unfavorable situation found in the work environment of gas station attendants.

The issue of the need to use PPEs to guarantee the physical integrity of these professionals is under discussion due to the obstacles related to the effects of not using essential equipment, which demonstrated that fuel inhalations (toxic to human beings) and fuel explosions in establishments (flammable) have gradually become more common in the daily lives of gas station attendants [2].

From this perspective, it is essential to evaluate the social, economic, technological, and organizational factors interconnected by the work environment of the gas station attendants [3]. So, this study plans to present the obstacles observed by the attendants and to amplify the discussions about the nature of the chemical composition of gasoline.

This work highlights, exemplifies, and solidifies the resistance to the PPE by gas station attendants. Therefore, evidencing the consequences of not using such equipment. In this scenario, the choice of theme assumes that we can mitigate the risks faced by gasstation attendants with PPE. However, the lack of information regarding the need for such equipment has an impact on their well-being. We justify, therefore, this study by the use, or not, of PPE by gas 
station attendants in Salvador-BA, Brazil, based on descriptive statistics in the year 2021.

Therefore, aiming to mitigate the long-term effects of not using PPE on the health of these workers, this research proposes to express that the resistance to the PPE by gas station attendants is harmful to the physical and psychosocial variables.

\section{Theoretical Referential}

In this section, we divided into three parts, the chemistry present at gas stations, such as gasoline and itsmain characteristics, wasinitially studied.In addition, the relationship of gas station attendants with PPE and the main consequences of inhaling toxic compounds inherent in gasoline. Because of this study, to certify and support this research, we used the followed references:

a) Neto (2012) [4] exemplifies the need to use PPE due to the risks of gasstations combined with Regulatory Standard 20 that explains the management of health and safety in environments with flammable materials.

b) Moraes (2003) [5], Machado (2015) [6], Moreira and Gomes (2011) [7], Costa and Goldbaum (2016) [8] discuss the physicalchemical characteristics of gasoline together with the MSDS study provided by BR Distributing Company.

c) Marinho (2011) [9] brings in his book about the process of Atmospheric Distillation in the Oil Industry.

d) Rocha, Cezar-Vaz, Almeida and colleagues (2014) [1] addresses the risks that gas station attendants are exposed to chemical components.

e) Soares (2019) [2] highlights the negligence in PPE's use by these workers, addressing the factors that influence this issue.

f) Regulatory Norm Brazil (NR) 6 lists the application of PPE in places that present risks to their workers [10].

g) Regulatory Norm Brazil (NR) 15 applies to the issue of unhealthy conditions, a feature present at gas stations [11]. h) Campos (2017) [12] discusses the essentiality of gas station attendants knowing the consequences of exposure to gasoline.

i) D'alascio, Menegali, Bornelli, and Magajewki (2013) [13] explain the effects of benzene in the human body.

\section{Chemistry at Gas Stations}

Fuels, in general, are used by society as a means of obtaining energy for transportation. In this sphere, NR 20 [10] classifies gas stations as class I, so that they are classified as a service that has flammable materials. Thus, it is first necessary to understand how gasoline, of fossil origin, present in gas stations, is obtained through atmospheric distillation in the Petroleum Industry.

In a simplified way, the work "New Chain of Oil and Natural Gas" conceptualizes atmospheric distillation as the "fractionation of crude oil to be processed in all "refineries" and, therefore, the gasoline goes through this process, to be sent to the fuel distribution networks and, finally, to the final consumer, through the handling of gas station attendants [9].

Figure 1 shows the oil refining process, in which crude oil undergoes a heating process to raise the temperature of this oil and, subsequently, goes to the atmospheric distillation tower, which obtains the fractions of petroleum, such as gasoline, the main chemical component to be studied in this article.

So, exposure to the chemical components of gasoline generates the need for PPE use due to the risks presented [4].

\section{Gasoline}

Gasoline is the principal fuel used to fuel vehicles. Similarly, it isthe product that gasstation attendants are exposed to in their workplace.

In Brazil, there are several types of gasoline. However, our analysis used the general chemical nature of this substance, which is used for internal combustion engines with ignition [9]. 
Figure 1. Oil refining.

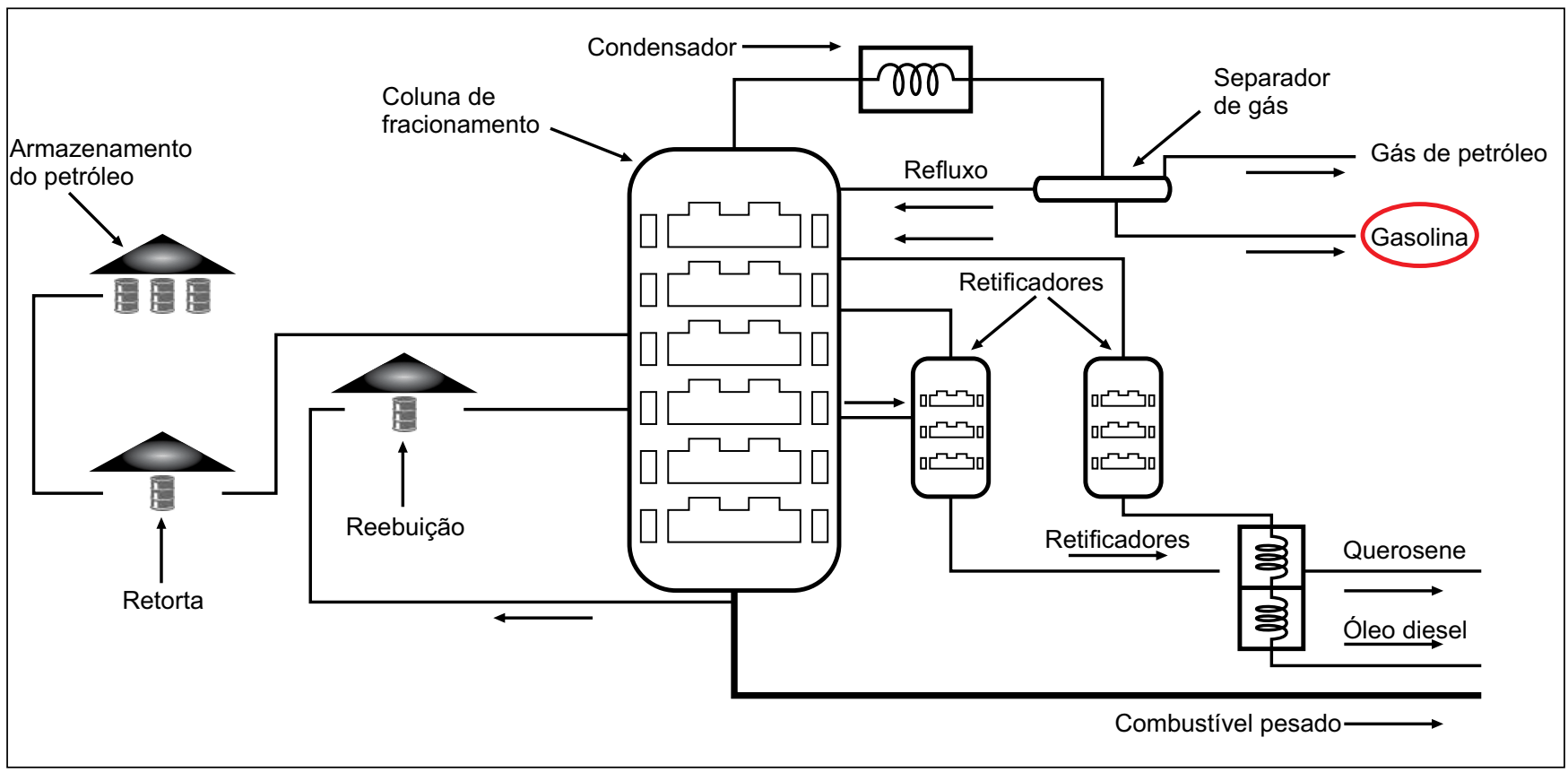

Source: Luciana Mendonça (2011) [19].

In this context, it is crucial to evaluate the gasoline physical-chemical characteristics to understand why it is necessary to use such equipment.

The principal characteristic is the organic composition. It is a naphtha complex, substances with hydrocarbons, carbon chains from $\mathrm{C} 5$ to $\mathrm{C} 12$, including paraffinic, olefinic, and aromatic hydrocarbons, and boiling range from -20 to $230^{\circ} \mathrm{C}[15]$.

Therefore, the volatility of this chemical component is a crucial characteristic. It poses high risks for gas station attendants when they fill the vehicles' tank because of the inhalation - evaporation facilitates - of the chemical compounds present in gasoline.

Within the analysis aspects of gasoline, the octane of this compound is an indicator of the performance of this chemical under varying engine operating conditions [5].

The conditions are high pressure and high temperature, thus creating a spontaneous detonation resistance inside the combustion chamber, in which the mixture between fuel vapor and the air is pushed to the maximum limit. The octane follows the chemical composition of gasoline, called the octane number or octane number.

Thus, gasoline is a component with several mixtures of multicomponent. We use two references to delimit the octane number, the regular- heptane defined as ZERO, as it has low compressive strength and iso-octane (2,2,4 Trimethylpentane) as a parameter for presenting high compressive strength [6].

After evaluating the volatility and octane of gasoline, it is essential to understand hydrocarbons, which can be paranific, olefinic, and aromatic, the latter being the most aggressive to the human body.

\section{Benzene}

Benzene (C6H6) - aromatic compound - has exposed the employees to toxicity in medical literature since the 19th century [7]. In this 
analysis, this toxicity is related to the worsening of hematotoxicity, problems related to blood circulation, and genotoxicity, related to the mutagenic and carcinogenic capacity, resulting from its metabolism [8].

Figure 2 shows the risks generated by the inhalation of gasoline, arising from the completion of refueling. So, the PPE use could avoid nervous system disease, genetic changes in human cells, and other systematic disorders due to gas inhalation.

According to the Chemical Product Safety Data Sheet (MSDS) for gasoline, the toxicological characteristics to which gas station attendants are exposed are: acute toxicity - orally -, which can generate nausea and vomiting, corrosion and skin irritation, eye damage, respiratory sensitization, germ cell mutagenicity, carcinogenicity, and reproductive toxicity.

Thus, the exposure of attendants must be minimized to ensure their health.

\section{Relationship Between Gas Station Attendants $x$ PPES}

Gas stations present risks related to workers, who need to carry out their activities, namely: contact with chemical products, noise, heat, and inhalation of chemical compounds such as aromatics, which are offensive to the attendants' health and life-quality at their workday [1].

The NR-20, a classification established in the SIT (Labour Inspection Secretariat) Ordinance No. 787 , informs the minimum requirements for the management of safety and health at work against risk factors for accidents in extraction, production, storage activities, transfer, and handling of flammable products and combustible liquids [10].

Hence, the commercialization of fuels and flammables requires inspection and monitoring. It is of great importance for gas station workers who are exposed to these chemical products' commercialization activities.

In addition, Regulatory Norm Brazil (NR) 15, which was originated by SIT Ordinance No. 787, in which it is related to activities that must be classified as unhealthy, thus generating unhealthy bonusesfor workers who deal with noise exposure, ambient heat, ionizing radiation, and chemical agents containing benzene, in which the attendants are subject to these situations [11].

Thus, as a solution or improvement in the quality of life and health for this category of employees, Regulatory Standard 6, which is in STI Ordinance No. 787, which regulates the execution of work with the Personal Protective Equipment (PPE), regardless of sector or economic or commercial activity. Furthermore, the obligation to provide the supply and PPE for employees and workers, including gas station attendants, who have specific protective equipment to combat the risks present in the workplace [6].

Therefore, the realities present in these places are inconsistent with the regulatory standards, which aim to ensure individuals who work with flammable products, in which the attendants refuse to apply these NR, taking high risks to their well-being and health.

\section{Resistance to the PPES}

The reason that causes resistance in the application of PPE by gas station attendants is that they "claim" discomfort when using it, forgetfulness, non-supply equipment, and, finally, underestimating the risks present at gas stations. In addition, inadequate physical structures conditions at the workplace contribute to low adherence to PPE use. For example, exposure to heat is a risk for workers [2].

So, the resistance to using protective equipment makes the work environment highly dangerous and unhealthy for all employees. Furthermore, the non-performance of inspection by public bodies related to Work Safety (ST) facilitates workers not complying with the obligations established by the Regulatory Norms (NRs) [10,11].

In addition, the non-provision of PPE by companies and station owners, who should distribute according to NR-6 to gas station attendants, to make a safer work environment 
Figure 2. Gasoline as the main villain for the health of gas station attendants.

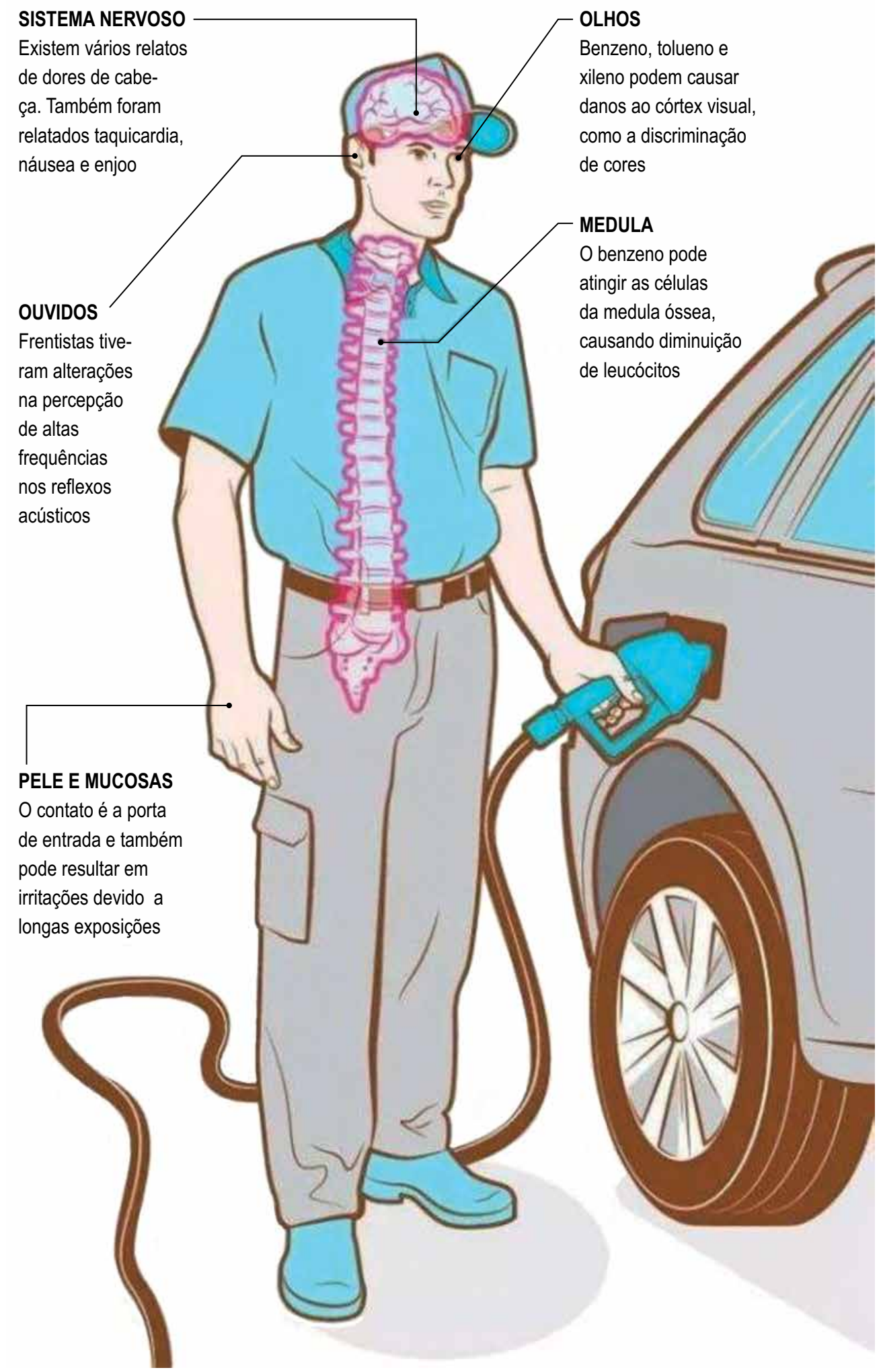

Source: Brazil Postos (2014) [20]. 
and thus prevent occupational diseases, such as the inhalation of chemical products, specifically benzene, which is present in the composition of gasoline [18].

\section{Lack of PPE by Gas Station Attendants}

The effects caused by the absence of Personal Protective Equipment are, mostly, harmful to the health of attendants.

When evaluating the effects generated by the absence of PPE, first, occupational diseases that may eventually affect gas station attendants are highlighted. In this context, exposure to benzene, an aromatic compound present in gasoline, is the main precursor of the adversities found in the human body. Thus, it is up to the National Occupational Health Policy in Brazil to establish means to expose a situational and preventive diagnosis for these workers [12].

First, it is necessary to understand the concept of 'Benzenism': "Benzenism is a set of signs, symptoms, and complications resulting from acute or chronic exposure to benzene. Complications can be acute, when there is exposure to high concentrations with the presence of neurological signs and symptoms, or chronic, with different clinical signs and symptoms, and complications may occur in the medium or long term, located mainly in the hematopoietic system (bloodforming). [14]" In this analysis, it is known that benzene can enter the human body, mainly through the airways, but the skin and ingestion may also be considered modes of absorption. Similarly, immediate contact with benzene irritates the mucous membranes which, over time, can cause pulmonary edema and hemorrhage in contact areas, causing death [17].

Thus, the intense contact with this compound may, initially, characterize mild symptoms that, later, with advancing exposure, may result in a slow but aggressive degeneration for human health.

So, Figure 3 showsthe form of contamination due to the chemical compound benzene, such as, through inhalation, contact with the skin, and ingestion, leading to problems in the systems of the human body.

Analyzing the effects of benzene on the human body, the nervous alterations are drowsiness, headache, vertigo, and tremors, and the hematological alterations, due to damage to the bone marrow, the blood-forming tissue, are given by anemia, leukopenia, lymphocytopenia, thrombocytopenia, coagulation disorders, and recurrent infections [13].

In short, this study highlights the consequences generated by the lack of PPE by gas station attendants, thusthe great possibilityof occupational diseases with exposure and inhalation of chemical components, specifically benzene, causing disease in the blood and respiratory streams, in which to solve or minimize the diseases and the supply of PPE by companies responsible for gas stations and the application of PPE by gas station attendants.

\section{Materials and Methods}

This research, based on a case study, used articles with several theorists, present in several scientific websites, such as Academic Google, Scielo, "Research Gate", UFERSA Library, and UFRJ Library, to use bibliographic research so that they can legitimize the issues highlighted in the objectives of this research. In addition, descriptive statistics were used, through a questionnaire, at gas stations in Salvador-BA, to prove that the situations portrayed in this article are part of the daily lives of gas station attendants. Finally, after analyzing the responses collected, which were 10 gas station attendants, the relevance of the present study was evidenced through the results.

\section{Results and Discussion}

According to Marconi and Lakatos (2003) [16], the results of a case study are the most important part of the research. Because of this, this topic will evidence the data we collected at the Salvador-BA gas stations between April and May 2021. 
Figure 3. Benzene intoxicating pathways.

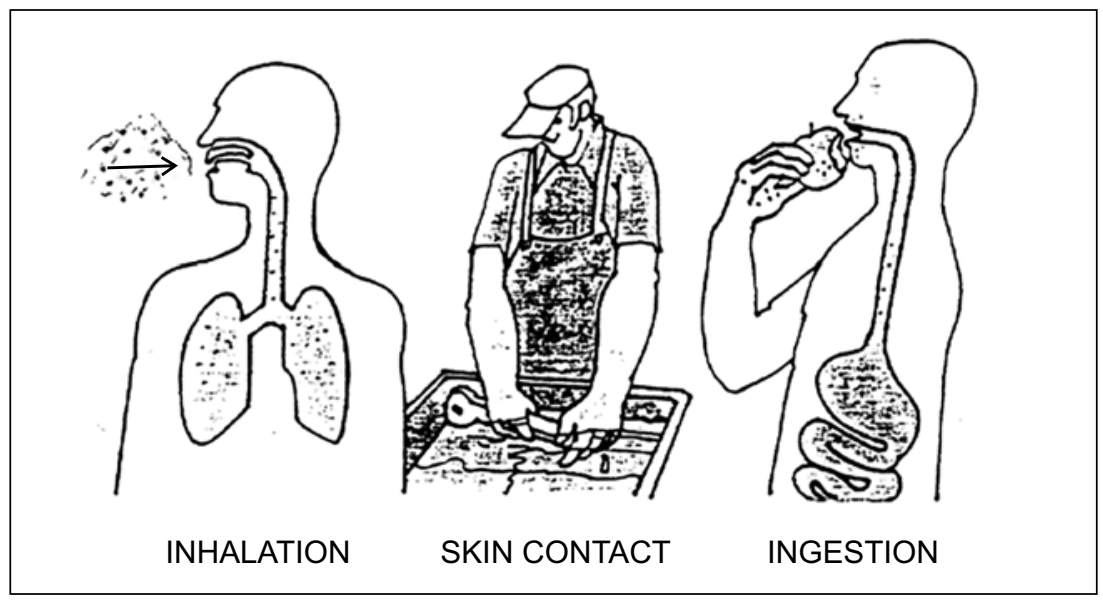

Source: BT CDC (2011) [21].

We divided the questionnaire into foursections: general information, consciousness about PPE, knowledge about the risks involved, and receiving PPE.

The first analysis was carried out in a general way regarding age, length of service, and level of education, which are crucial categories for assessing socioeconomic factors. In this analysis, more than half of the gas station attendants fall into the category between 40 and 60 years old. Then, $30 \%$ were between 25 and 40 years and, finally, only 1 of the interviewees was between 18 and 25 years.

In addition, it appears that the length of service varied among most of the gas station attendants interviewed. In this sense, $40 \%$ have been working for 10 to 15 years. This information matches our interviews: 0 to 5 years, 5 to 10 years, and 15 to 20 years, each presenting a percentage of $20 \%$. Finally, the level of education shows that 9 out of 10 respondents have High School. After analyzing these three socioeconomic variables, the second session of the questionnaire: factors related to PPE at gas stations (Graph 1).

Initially, given the importance of using PPE, $90 \%$ of the attendants answered that they know the concept of this equipment, which characterizes a positive characteristic for this project, as it proves that the references used showed that the attendants knew about the PPE, but, later, we showed that they, despite knowing, do not use properly. Then, the gas stations provide PPE to their workers, complying with NR 6 . On the other hand, although $70 \%$ of the attendants are aware that the stations have to provide such equipment, $30 \%$ are still not aware of this information, which hinders the dissemination of protected information to the attendant. In the background, the charts below present essential safety factors for these workers (Graph 2).

From these graphs, it is worth emphasizing, at first, that training on how PPE should be done is essential to ensure the consistent use of this equipment since misuse can cause damage in the same way as non-use. In this aspect, $70 \%$ of the attendants stated that they received training, ensuring that they use it correctly. However, inspection to guarantee the use of PPE does not occur at most gas stations, which, notoriously, is at odds with the study proposed by Soares (2019) [2]. In this bias, safety management (NR-20) should enhance to guarantee the use of PPE by gas station attendants [10]. Therefore, the variables questioned by the attendant were analyzed.

Although the attendants - in their entirety consider the use of PPE important in their services, it was evident that $50 \%$ of the interviewees did not use this equipment for their safety. The lack 
Graph 1. About PPEs' knowledge.

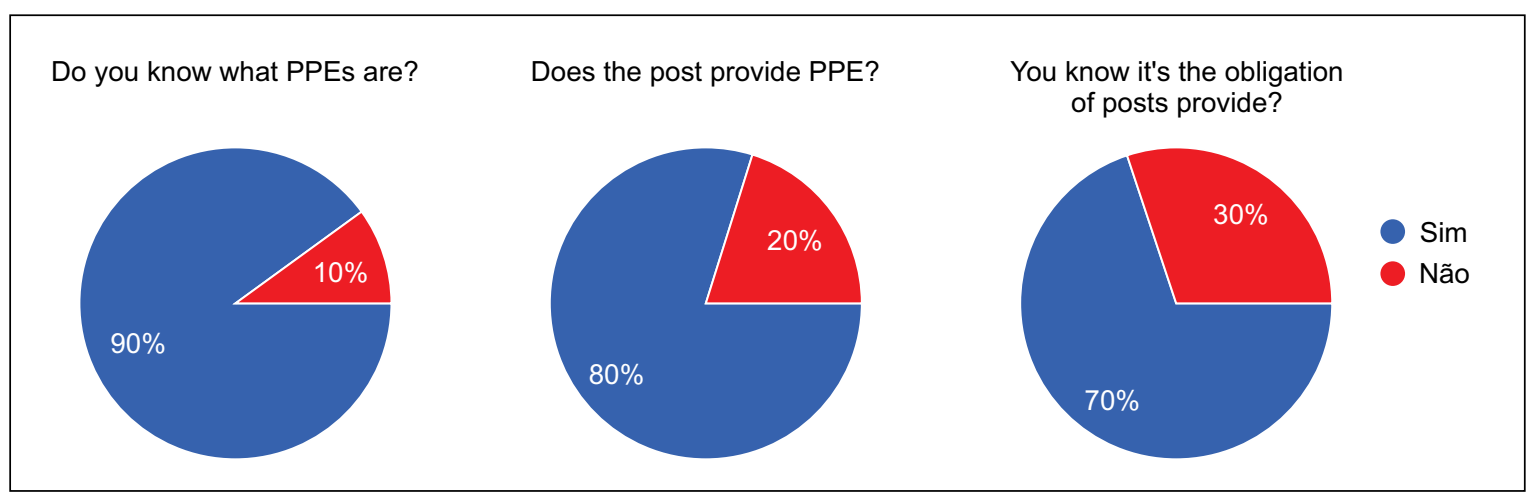

Graph 2. Trainning and supervision to PPE.

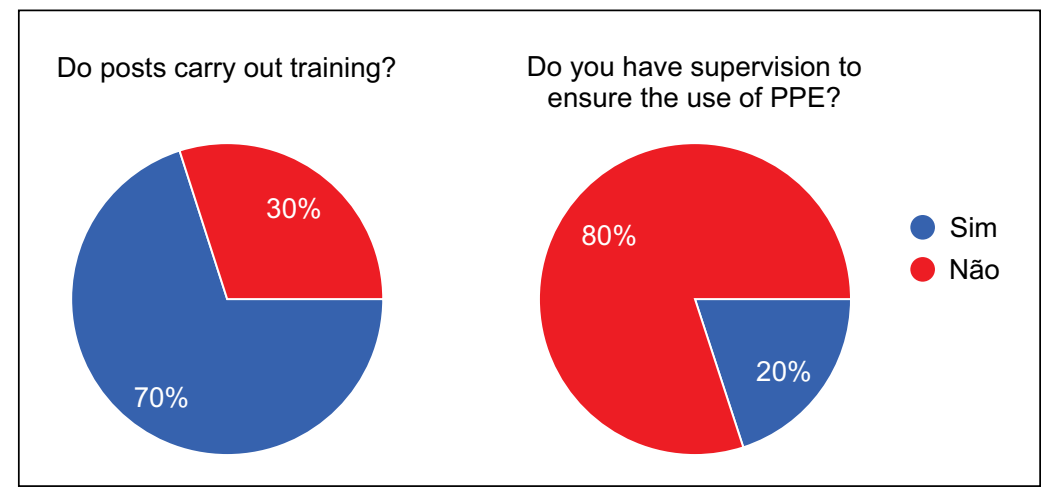

of inspection at gas stations, which would explain such resistance from these professionals, can explain this percentage (Graph 3). Such questions are necessary: Would inspection guarantee the use of PPE by gas station attendants? Do gas station attendants need to be scrutinized for their safety? If attendants used PPE, would inspection be essential to ensure safety or just by protocol? About the benzene, $70 \%$ of the gas station attendants said they had prior knowledge about gasoline and $30 \%$ said they did not. However, this is not justified since the training carried out by gas stations should include using PPE: avoid contacting the compounds present in gasoline. About benzene, $90 \%$ claimed to know about this aromatic compound. Nevertheless, the workers were not aware of the consequences that the possible contact could cause on their health.

The third session of this study deals with the risks involved in this type of work. The question asked was: What risks do you believe you are being exposed to? (Graph 4).

According to Graph 4, exposure to benzene by handling fuels can lead to eye contact, inhalation of vapors, repeatability, fire and explosion, skin contact, intense activity, and contamination fuels themselves are the main complaints of gas station attendants, which proves the main objective of this study.

The data on risks of rupture and leakage, physical and muscular effort, fuel storage, equipment breakdown, repetitiveness, and intense activity were other complaints portrayed, but not in their entirety.

The last session of the questionnaire developed by the authors is about the receipt of PPE, which, as shown above, is the obligation of gas stations to provide gas station attendants. But, it is not 
Graph 3. Dealing of PPEs.

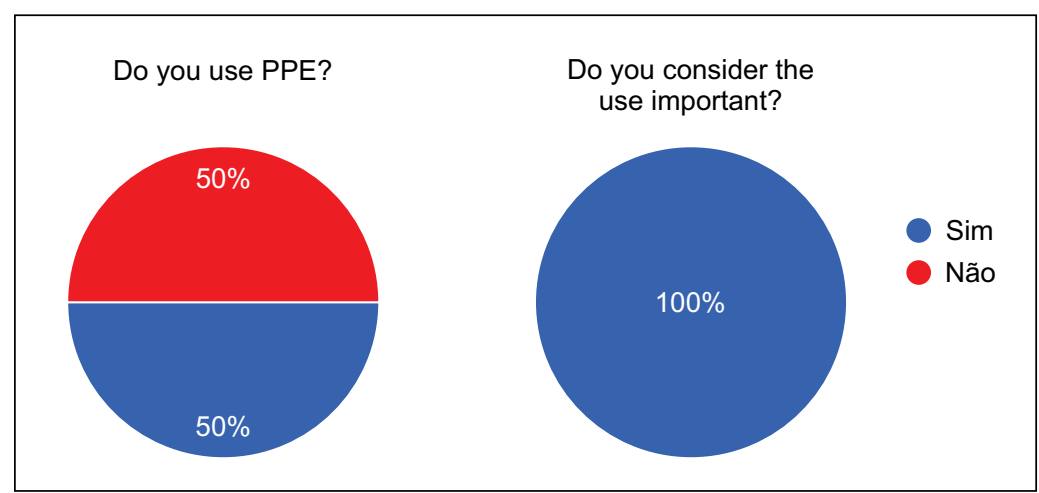

Graph 4. Involved risks without PPEs.

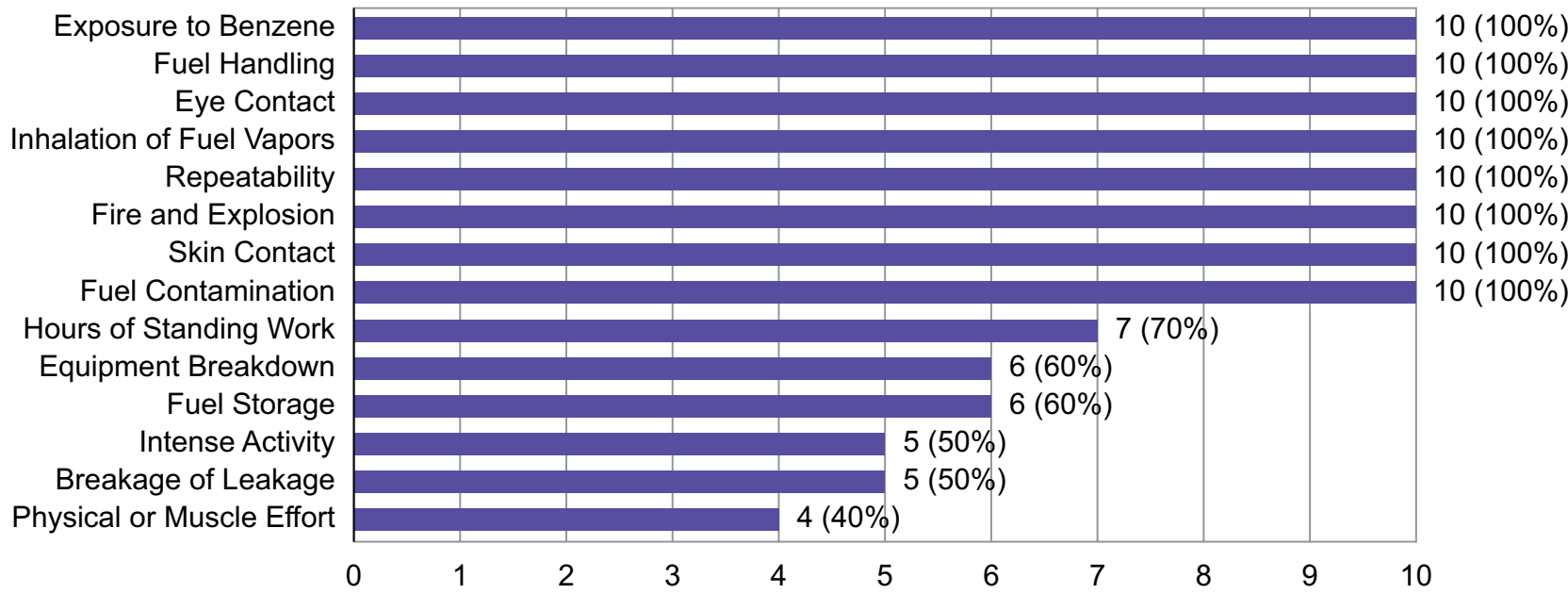

Graph 5. PPEs' use by attendants.

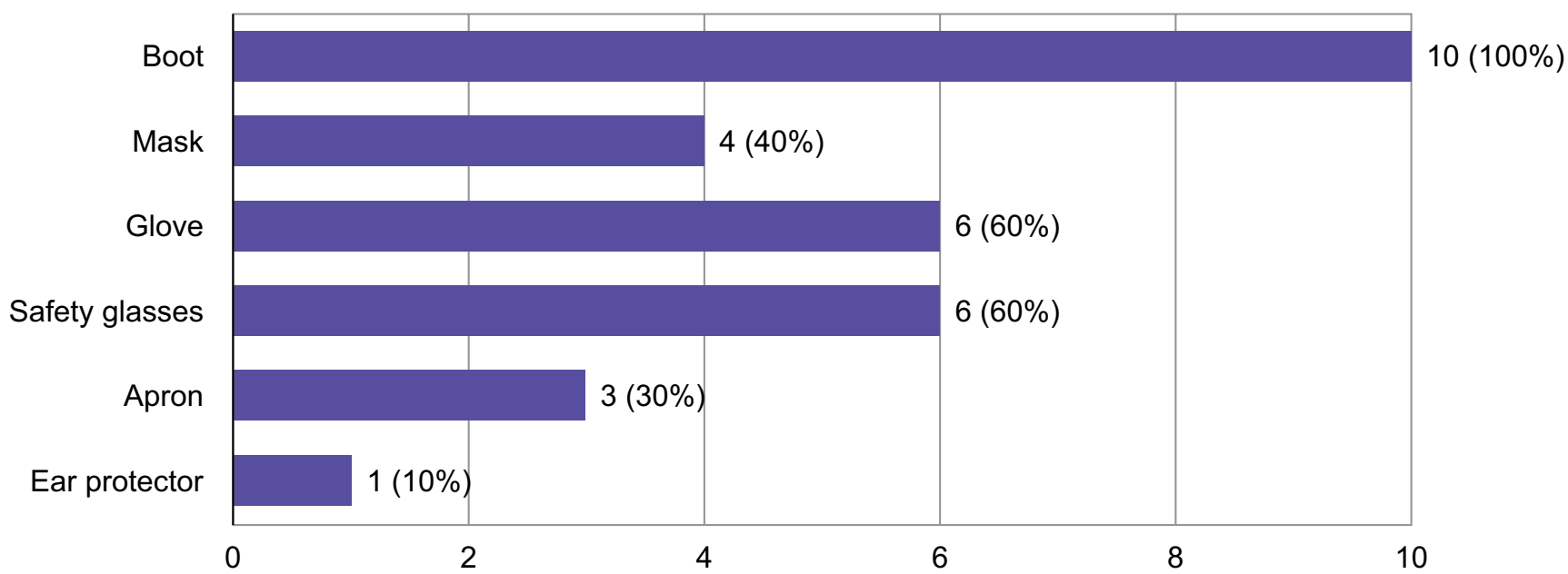


always carried out, thus causing safety problems for attendants (Graph 5).

According to Graph 5, the boot is the PPE most provided by the posts since all respondents claimed to receive it. From a health perspective, the majority supply of the boot is at odds with the explanations of the International Agency for Research on Cancer (2012) [17], as it states that the main route of exposure to benzene is respiratory. Agreeing with the Agency, the provision of a mask should be the principal equipment available. Nevertheless, less than half of the respondents receive this equipment. Furthermore, $60 \%$ of the attendants said they received gloves to use in their respective work environments, minimizing the contact with products with toxic chemical compounds, thus exemplifying the need for such equipment to prevent contact with human skin. Therefore, the PPE is necessary to mitigate all factors collected at gas stations in Salvador-BA.

\section{Conclusion}

The PPE is necessary to avoid future consequences for gas station attendants. From the data collection, we observed attendants are being exposed to daily risks without any inspection to prevent them. We also noted the lack of information between them and the resistance to PPE use since there is no inspection at gas stations. Therefore, by entering the discussion of a very relevant but little-discussed topic, the doors for future research are opened, as by looking at safety and health, it is possible to understand the many facets of these workers.

\section{Acknowledgments}

We thank the professors who helped us during the article creation process, especially Mr. Wadson Barbosa. In addition, we would like to thank the coordination of our technical course, Mrs. Nayara Oliveira. We also thank our classmates throughout the course. We thank each other (Ananda and Vitor) for all the construction of this project, which, for sure, would not be possible without our partnership. And finally, we thank the SENAI CIMATEC Institution for our technical training in Petrochemicals. Without all this support network, it would not be possible for us to obtain this opportunity to publish our article at the SIINTEC symposium in 2021. Thank you all.

\section{References}

1. Rocha L, Cezar-Vaz MR, Ameida M, et al. Use of personal protective equipment by gas station attendants: Contribution of nursing. Federal University of Rio Grande do Sul. 2014. Available at: Accessed on: 28 Mar 2021.

2. SoaresTN.Analysis ofthe conditionsforthe use of PPEs and the importance of awareness of their usefulness for the activity of gas atations in gas stations in the municipality of Mossoró - RN. Federal Rural University of the Semiarid (UFERSA) - Course Conclusion Paper, 2019. Available at: Accessed on: 23 mar 2021.

3. Potres MN. Perception of gas station attendants on the repercussionsoftheirprofessional activityon theirhealth in the city of Uberaba. 2008. 65 f. Dissertation (Masters in Exact and Earth Sciences) - Federal University of Uberlândia, Uberlândia, 2008. Available at: Accessed on: 23 mar 2021.

4. Neto VG. Importance of the use of PPE by gas station attendants in Salvador-BA. for. 18. 2012. SalvadorBA. (Article for Bachelor requirement) Available at: Accessed on: 26 Mar 2021.

5. Moraes JEB. Experimental module for fuel octane determination. 2003. Available at: Accessed on: 29 Apr 2021.

6. Machado JV. Isomerization of n-octane over Pt/ HBEA catalyst to improve the quality of gasoline. 2015. Dissertation (Masters in Chemical Engineering. Available at: Accessed on: 27 Apr 2021.

7. Moreira GG, Gomes S. Occupational poisoning from benzene: an environmental health issue. 2011. Available at: Accessed on: Apr 23, 2021.

8. Costa DF, Goldbaum M. Chemical contamination, precariousness, illness and death at work: benzene in Brazil. Ciência \& Saúde Coletiva [online]. 2017, v. 22, no. 8 pp. 2681-2692. Available at: https:// www.scielo. $\mathrm{br} / \mathrm{j} / \mathrm{csc} / \mathrm{a} / \mathrm{DGWMrgwdFGhZPzm6tr74qpL/?format}=\mathrm{p}$ df\&lang=pt $>$ Accessed on: 24 Apr 2021.

9. Marinho R. New oil and natural gas productive chain. Volume I. 1st Edition. Santa Cruz do Rio Pardo - SP: Editora Viena, 2011.

10. Ministry of Labor. MTB Ordinance No. 3.214, of June 8, 1978. NR 20, Regulatory Standard-6 (1978). Official 
Gazette of the Federative Republic of Brazil - Brasilia.

11. Ministry of Labour. MTB Ordinance No. 3.214, of June 8, 1978. NR 15, RegulatoryStandard-15 (1978). Official Gazette of the Federative Republic of Brazil Brasília.

12. Campos AG. Analysis of the activity of the attendant in face of the danger of exposure to benzene. 2017. 94 f. Dissertation (Academic Master's in Public Health) Instituto Aggeu Magalhães, Oswaldo Cruz Foundation, Recife, 2017. Available at: Accessed on: 23 Apr 2021.

13. D'alascio R, Menegali M, Bornelli A, Magajewki F. Symptoms related to occupational exposure to benzene and occupational habits in workers at retail fuel resale stations in the southern region of Santa Catarina. Rev Bras Med Trab. 2014;12(1):21-29. Available at: < https://cdn.publisher.gn1.link/ rbmt.org.br/pdf/ v12n1a04.pdf $>$ Accessed on: 29 Apr 2021.
14. Arcuri A, Costa D, Possebon J, et al. Benzene: it is not a flower to smell. São Paulo: FUNDACENTRO, 2011. Available at: Accessed on: 23 Apr 2021.

15. Chemical Safety Sheet: Gasoline. 2020. Available at: Accessed on: 23 apr 2021

16. Lakatos EM, Marconi MA. Methodology of scientific work. São Paulo: Atlas, 2003.

17. International Cancer Research Agency; 2012.

18. Vasconcelos S, Santos J, Soares MA, Santos MB. Health and safety analysis at fuel reseller stations in the Municipality of Campina Grande - PB. ENEGEP,7. 2009. Available at: Accessed on: March 23, 2021.

19. Marinho R. New Oil and Natural Gas Chain - Volume I. 2011. Publisher: Viena. $1^{\text {st }}$ Edition.

20. Attendant: Profession Danger. Galileo Magazine. 2014. Available at: Accessed on: 24 apr 2021. 21. Available at: Accessed on: 24 apr 2021. 